\title{
Magnesium Concentration in Cerebrospinal and Brain Interstitial Fluid Correlates with Serum Level in Induced Hypermagnesemia
}

\author{
Kajetan L. von Eckardstein ${ }^{1,2}$, Jürgen C. W. Kiwit ${ }^{2}$, Ulf Westhause ${ }^{2,3}$, Veit Rohde ${ }^{1}$, \\ Andreas Spuler ${ }^{2}$ \\ ${ }^{1}$ Department of Neurosurgery, Universitätsmedizin Göttingen, Göttingen, Germany \\ ${ }^{2}$ Department of Neurosurgery, HELIOS Klinikum Berlin-Buch, Berlin, Germany \\ ${ }^{3}$ Department of Neurosurgery, Klinikum Chemnitz, Chemnitz, Germany \\ Email: kajetan.voneckardstein@med.uni-goettingen.de
}

Received 9 March 2016; accepted 19 April 2016; published 22 April 2016

Copyright (C) 2016 by authors and Scientific Research Publishing Inc.

This work is licensed under the Creative Commons Attribution International License (CC BY). http://creativecommons.org/licenses/by/4.0/

(c) (i) Open Access

\begin{abstract}
Being a modulator of the N-methyl-D-aspartate (NMDA) receptor function magnesium has been studied for its neuroprotective and vasodilatative properties in acute and delayed brain ischemia due to vasospasm in aneurysmal subarachnoid haemorrhage (aSAH) and stroke. A number of clinical phase II and III studies have correlated serum magnesium concentrations after intravenous continuous application to clinical outcome and have failed to show a positive therapeutic effect. However, no study supported its conclusion by providing evidence for a local increase in magnesium, i.e. in the cerebrospinal fluid (CSF) and the brain parenchyma. The objective of our observational study was to compare magnesium levels in serum, CSF, and brain microdialysis samples (MDS) in patients with aSAH. Seventeen patients with aSAH at World Federation of Neurosurgeons (WFNS) grade IV and V were included. According to our internal standard treatment protocols, all patients received a ventricular catheter, a frontal intracerebral microdialysis probe, and a continuous intravenous application of $80 \mathrm{mmol} \mathrm{MgSO}_{4}$ per 24 hours. Magnesium concentrations of serum, CSF, and MDS were recorded. We found a positive and significant correlation of increased serum levels of magnesium to CSF and MDS magnesium concentrations. These pharmacokinetic findings may serve as a basis for further discussion of the concept of induced hypermagnesemia in patients with aSAH, especially in the context of recent level A evidence of the lack of clinical benefit.
\end{abstract}

\section{Keywords}

Aneurysm, Magnesium, Microdialysis, Subarachnoid Hemorrhage, Vasospasm

How to cite this paper: von Eckardstein, K.L., Kiwit, J.C.W., Westhause, U., Rohde, V. and Spuler, A. (2016) Magnesium Concentration in Cerebrospinal and Brain Interstitial Fluid Correlates with Serum Level in Induced Hypermagnesemia. Open Journal of Modern Neurosurgery, 6, 82-87. http://dx.doi.org/10.4236/ojmn.2016.62015 


\section{Introduction}

Interest in magnesium as a neuroprotectant and antivasospastic agent for the therapy in cerebral aneurysmal subarachnoid haemorrhage (aSAH) and stroke, but also in perinatal hypoxia, has risen over the last couple of years, but declined after publication of a phase III international multicenter placebo controlled trial (MASH-2) [1] and a meta-analysis [2] in 2012, both concluding that prophylactic intravenous magnesium does not improve neurological outcome in patients with aSAH. Since the first description of reversal of delayed cerebral vasospasm by magnesium in rats [3] and a pilot study on the management of patients with a Fisher Grade 3 aSAH [4], numerous case studies [5] and larger dose finding clinical study [6] were published, partially with good and promising clinical outcomes [7]. An animal study on transient focal cerebral ischemia in rats concluded that a serum magnesium level between 2.0 and $3.0 \mathrm{mmol} / \mathrm{L}$ offered best protection [8]. None of the aforementioned studies, however, correlated the dependent variable (e.g. clinical outcome, Doppler ultrasound examinations, neuroradiological or neuropathological studies) with the level of magnesium in either cerebrospinal fluid (CSF) or brain parenchyma but only to serum levels.

The rational of magnesium application for the treatment of cerebral vasospasm and stroke is mainly based upon the voltage-dependent blockage of the N-methyl-D-aspartate (NMDA) receptor [9] which effects cellular energy metabolism, vascular tone, and cell membrane transport [10]. Magnesium causes vasodilatation by stimulation of endothelial prostacyclin release and prevents vasoconstriction by a variety of mediators [11].

The aim of our study was to investigate the correlation of magnesium concentration in serum $\left(\left[\mathrm{Mg}^{2+}\right]_{\text {serum }}\right)$, $\mathrm{CSF}\left(\left[\mathrm{Mg}^{2+}\right]_{\mathrm{CSF}}\right)$, and microdialysis samples $\left(\left[\mathrm{Mg}^{2+}\right]_{\mathrm{MDS}}\right)$ with increase of serum magnesium level below 3.0 $\mathrm{mmol} / \mathrm{L}$ by continuous intravenous magnesium application. In humans, this correlation has not been established so far. This missing information is needed for further evaluation and discussion of the failed clinical studies. For the purpose of this study $\left[\mathrm{Mg}^{2+}\right]_{\mathrm{MDS}}$ was considered a surrogate parameter for magnesium concentration of the cerebral extracellular fluid $\left(\left[\mathrm{Mg}^{2+}\right]_{\mathrm{ec}}\right)$, a direct linear correlation had been shown between the concentration of magnesium ions in the medium surrounding the dialysis membrane (i.e. $\left[\mathrm{Mg}^{2+}\right]_{\mathrm{ecf}}$ ) and the concentration measured in the collected perfusate (i.e. $\left[\mathrm{Mg}^{2+}\right]_{\mathrm{MDS}}$ ) [12].

\section{Material and Methods}

\subsection{Patients}

In this observational study we have included 17 consecutive intubated patients with aSAH World Federation of Neurosurgeons (WFNS) Grade IV and V. For the purpose of this study, which was done in accordance with the local ethics committee in between 2004 and 2006, the routine diagnostic and therapeutic schedule was not altered. Following our standard treatment protocol, these patients received a ventricular drain and a frontal intraparenchymal microdialysis bolt catheter to analyze typical standard parameters (lactate, pyruvate, glucose, glutamate). Furthermore, these patients received a continuous intravenous magnesium sulphate $\left(\mathrm{MgSO}_{4}\right.$, Casella-Med, Cologne, Germany) application of $80 \mathrm{mmol} \mathrm{MgSO}_{4}$ per 24 hours. Serum magnesium was not to exceed $3.0 \mathrm{mmol} / \mathrm{L}$ to avoid toxic effects. The measurements started before the initial application of magnesium and were carried through until either the ventricular drain or the microdialysis probe was removed.

In addition, 15 comatose patients with a diagnosis other than aSAH, who had a frontal intraparenchymal microdialysis bolt catheter for other indications, $\left[\mathrm{Mg}^{2+}\right]_{\mathrm{MDS}}$ and $\left[\mathrm{Mg}^{2+}\right]_{\text {serum }}$ was measured as a by-product. However, these patients typically did not have intraventricular lines to collect CSF samples.

Due to the limitations of the study we did not match clinical outcome or vasospasm scores with magnesium measurements.

\subsection{Microdialysis and Measurements}

Microdialysis was performed using a catheter with a membrane length of $10 \mathrm{~mm}$ and a cut-off at 20.000 Dalton (CMA 70, CMA Microdialysis AB, Solna, Sweden). The pump rate was $0.3 \mu 1 / \mathrm{min}$ of $\mathrm{Mg}^{2+}$ free perfusion fluid (perfusion fluid T1, CMA Microdialysis AB). Serum and CSF was collected once a day, microdialysis specimens were collected twelve times a day (every two hours) and pooled daily after analysis for standard parameter to yield sufficient dialysate for $\mathrm{Mg}^{2+}$ analysis. The daily analysis of CSF, serum, and microdialysis specimens for magnesium concentration was done in the hospital laboratory using a standard colorimetric endpoint method with xylidil blue. 


\subsection{Statistics}

The raw data were adjusted using the ICU pilot software (CMA Microdialysis AB), the mean and standard deviation was calculated using Windows Excel and GraphPad Prism 2.0.

\section{Results}

\subsection{Patients with Magnesium Application}

We identified 17 (6 male/11 female) consecutive patients with a WFNS grade IV (8 patients) and V (9 patients) aSAH who received a standard ventricular drain, a frontal implantation of a microdialysis probe, and an intravenous continuous magnesium application. However, not all initially planned samples could be collected from every patient due to technical reasons (e.g. failure of the microdialysis pump, clotted external drain). The daily average number of collected specimens from day 0 to day 8 were 8.1 MDS specimens (range: 6 to 11 specimens), 9.0 CSF specimens (4 - 12), and 11.8 serum specimens $(8-14)$. In none of the patients magnesium application had to be adjusted to comply with the maximum serum level of $3.0 \mathrm{mmol} / \mathrm{L}$.

At three months, of all patients under observation 13 patients reached a Glasgow outcome scale (GOS) below or equal 3, two patients had a GOS of 4, and two patients had a full recovery (GOS 5).

We did not observe any cardiotoxic effects or unexplained cardiopulmonary events due to application of magnesium during or after the observation period, although magnesium application was carried on for as long as 26 days in selected patients at the dosages specified above.

\subsection{Patients without Magnesium Application}

Furthermore we identified 15 comatose patients with diagnoses other than aSAH who also had a microdialysis bold catheter (six patients with spontaneous intracerebral haemorrhages, seven patients with head trauma, and two patients with malignant brain ischemia). Typically, these patients did not have an external ventricular drainage and were not given magnesium. The daily average number of collected specimens from day 0 to day 8 was 7.6 MDS specimens (range: 1 to 16 specimens) and 7.8 serum specimens (1 - 15).

\subsection{Magnesium Measurements}

We observed an increase of $\left[\mathrm{Mg}^{2+}\right]_{\text {serum, }}\left[\mathrm{Mg}^{2+}\right]_{\mathrm{CSF}}$, and of $\left[\mathrm{Mg}^{2+}\right]_{\mathrm{MDS}}$ over time after intravenous application of magnesium in patients with aSAH (Figure 1). $\left[\mathrm{Mg}^{2+}\right]_{\text {serum }}$ peaked at day 3 after initiation of magnesium therapy

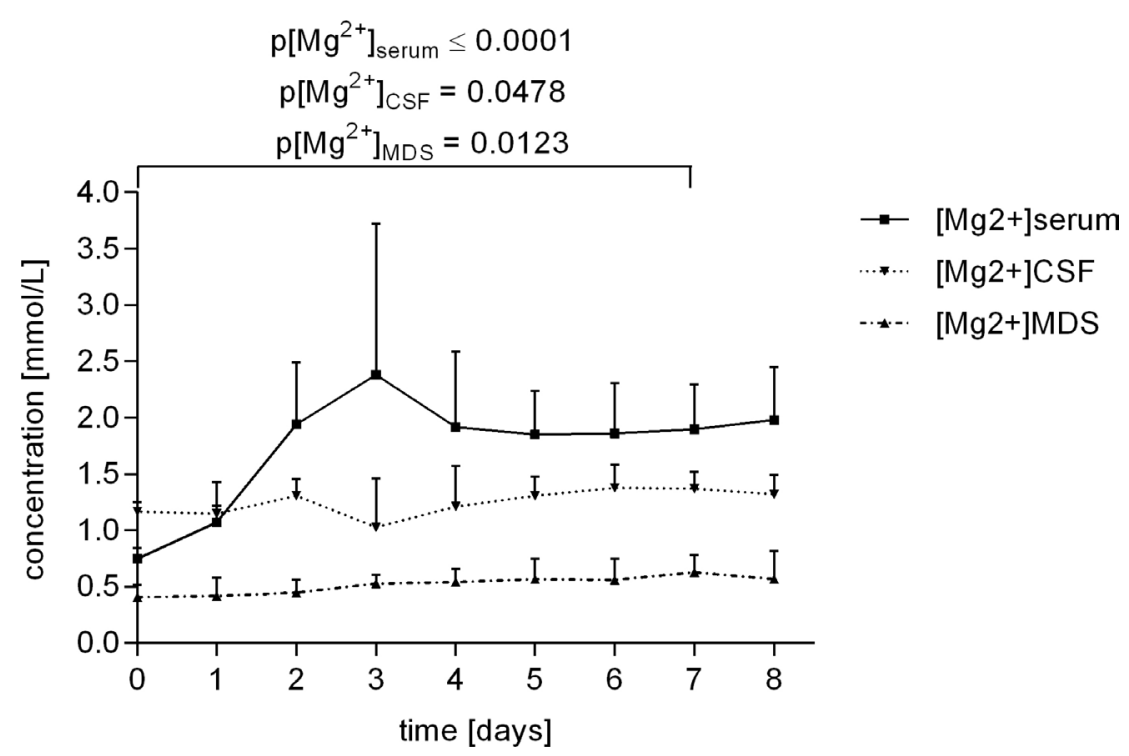

Figure 1. Mean and standard deviation of magnesium concentration [mmol/L] in serum, CSF, and microdialysis samples (MDS) in 17 patients with aneurysmal SAH and intravenous $\mathrm{MgSO}_{4}$ application at $80 \mathrm{mmol} / 24 \mathrm{~h}$. Differences between day 0 and day 7 are significant for all three parameters using the unpaired t-test. 
and fell to a plateau concentration of $1.9 \mathrm{mmol} / \mathrm{L}$ at day 7 , corresponding to a 2.53 -fold increase of the basal level. $\left[\mathrm{Mg}^{2+}\right]_{\mathrm{CSF}}$ reached a plateau phase of $1.4 \mathrm{mmol} / \mathrm{L}$ at day 7 , which is a 1.17 -fold increase. $\left[\mathrm{Mg}^{2+}\right]_{\mathrm{MDS}}$ slowly increased to $0.63 \mathrm{mmol} / \mathrm{L}$ at day 7 , therefore corresponding to a 1.53 -fold increase of the initial measurement. The unpaired t-test comparing day 0 to day 7 is significant for all three parameters (Figure 1), the nonparametic Wilcoxon test is only significant for increase of $\left[\mathrm{Mg}^{2+}\right]_{\text {serum }}$ and $\left[\mathrm{Mg}^{2+}\right]_{\mathrm{MDS}}(\mathrm{p}=0.028$ and $\mathrm{p}=$ 0.012, resp.).

In patients with diagnoses other than aSAH and without intravenous application of magnesium (Figure 2) we found a slight but not significant increase of $\left[\mathrm{Mg}^{2+}\right]_{\text {serum }}$ to $0.90 \mathrm{mmol} / \mathrm{L}$ at day $7(1.55$-fold), however, this increase did not result in a substantial increase in $\left[\mathrm{Mg}^{2+}\right]_{\mathrm{MDS}}(0.33 \mathrm{mmol} / \mathrm{l}, 1.06$-fold).

We further more have shown a significant positive correlation of $\left[\mathrm{Mg}^{2+}\right]_{\text {serum }}$ to $\left[\mathrm{Mg}^{2+}\right]_{\mathrm{MDS}}$ (Figure 3), suggesting a direct influence of $\left[\mathrm{Mg}^{2+}\right]_{\text {serum }}$ on $\left[\mathrm{Mg}^{2+}\right]_{\text {ecf }}$.

\section{Discussion}

We were able to show that a continuous intravenous application of magnesium sulphate does result in an increase of $\left[\mathrm{Mg}^{2+}\right]_{\mathrm{CSF}}$ and $\left[\mathrm{Mg}^{2+}\right]_{\mathrm{MDS}}$, the latter presumably representing an increase of $\left[\mathrm{Mg}^{2+}\right]_{\text {ecf }}$. We furthermore showed that the continuous intravenous dosage of $80 \mathrm{mmol} \mathrm{MgSO}_{4}$ per day was sufficient to increase $\left[\mathrm{Mg}^{2+}\right]_{\mathrm{MDS}}$ 1.5-fold without raising $\left[\mathrm{Mg}^{2+}\right]_{\text {serum }}$ above $3.0 \mathrm{mmol} / \mathrm{L} .5 \mathrm{mmol} / \mathrm{L}\left[\mathrm{Mg}^{2+}\right]_{\text {serum }}$ (severe hypermagnesemia) is known to interfere with the level of consciousness, $10 \mathrm{mmol} / \mathrm{L}\left[\mathrm{Mg}^{2+}\right]_{\text {serum }}$ can result in cardiac arrest [13].

In patients without continuous intravenous magnesium application, there was a slight and non-significant increase in $\left[\mathrm{Mg}^{2+}\right]_{\text {serum }}$, most probably due to magnesium additives in standard electrolyte infusion fluids. However,

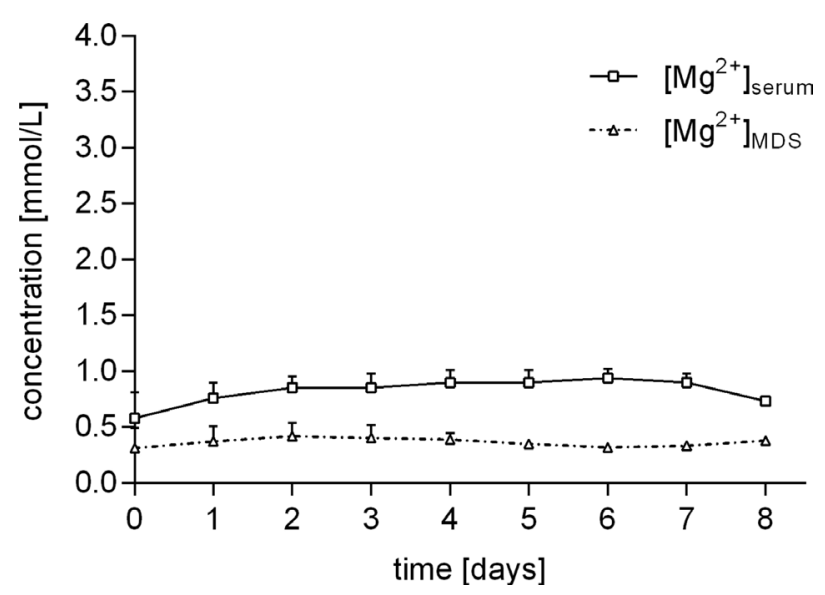

Figure 2. Mean and standard deviation of magnesium concentration [mmol/L] in serum and microdialysis samples in 15 patients with intracerebral haemorrhages, severe head trauma, and stroke without intravenous magnesium application.

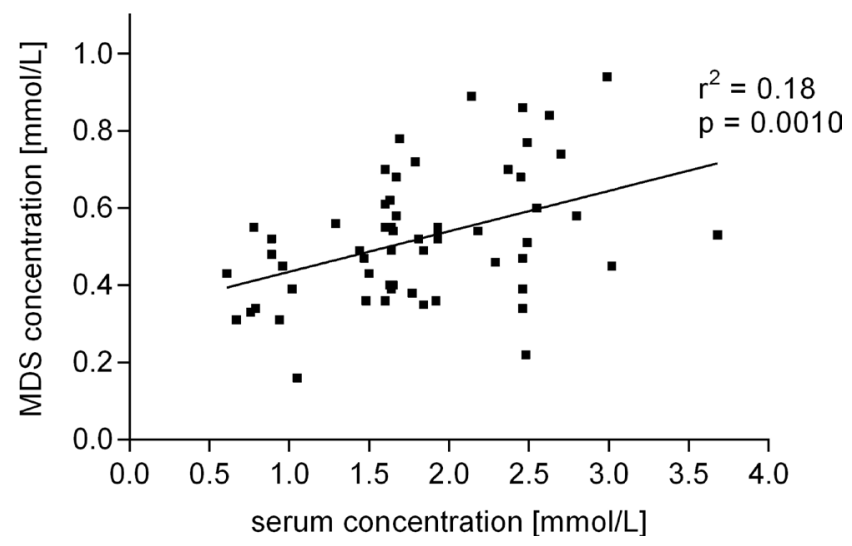

Figure 3. Highly significant positive correlation $(r=0.42)$ of the magnesium concentration $[\mathrm{mmol} / \mathrm{L}]$ in serum to microdialysis samples (MDS). 
this increase did not result in a measurable increase of $\left[\mathrm{Mg}^{2+}\right]_{\mathrm{MDS}}$.

In neurovascular diseases, extracellular magnesium has only been measured in animals by means of cerebral microdialysis. Magnesium administration has been shown to result in an increase of extracellular magnesium in miniswine [14]. It was shown in gerbils [15] that after cerebral ischemia and reperfusion, the level of magnesium dropped to $41 \%$ and gradually returned to $67 \%$ of baseline measurements, using an on-line automated microdialysis spectrometry for the measurements. The authors concluded that derangement of magnesium homeostasis could be important in brain cell injury. It was also shown that magnesium supplementation in gerbils may be beneficial in providing an additional glucose source and may also improve the recovery of energy substrates in the brain during and after forced exercise [16]. In earlier studies from the same group, common extracellular metabolites were measured in gerbils subjected to focal ischemia after pretreatment with magnesium [17]. Post-ischemic decreases of extracellular glucose and pyruvate were not as pronounced in the magnesium group compared to the control group. In our series, a similar decline of $\left[\mathrm{Mg}^{2+}\right]_{\mathrm{MDS}}$ was not found in patients with cerebral pathologies other than aSAH (Figure 2).

In trauma, however, there had been one report on magnesium microdialysis measurements in 43 patients, showing that the concentration of magnesium did not correlate to the extent of physiological deterioration [18]. Again, in the small and unselected group of seven trauma patients within our series, $\left[\mathrm{Mg}^{2+}\right]_{\mathrm{MDS}}$ did not change over time and the extent of brain destruction.

Few studies have focused on the issue of intracerebral magnesium distribution. By ${ }^{31} \mathrm{P}$ nuclear magnetic resonance (NMR) tomography, intracellular magnesium concentration $\left[\mathrm{Mg}^{2+}\right]_{\mathrm{i}}$ can be calculated in vivo [19]. The role and effects of an increase of $\left[\mathrm{Mg}^{2+}\right]_{i}$ remain poorly understood, but neuronal effects of an increase in $\left[\mathrm{Mg}^{2+}\right]_{\text {ecf }}$ are expected to be beneficial [14]. Further studies of extra- and intracellular distribution of magnesium in patients with SAH and continuous intravenous magnesium therapy are of interest, but difficult to perform.

A recent study on the brain bioavailability of intravenously administered magnesium in patients with acute brain injury concluded that induced hypermagnesemia of 2.1 to $2.5 \mathrm{mmol} / \mathrm{l}$ only marginally increased $\left[\mathrm{Mg}^{2+}\right]_{\mathrm{CSF}}$ [20]. Intravenous magnesium application was carried out for 24 hours and $\left[\mathrm{Mg}^{2+}\right]_{\mathrm{CSF}}$ was determined at baseline, twelve, 24, and 36 hours. The maximum increase was found to be $15 \%$. This corresponds to our data.

The issue of limited intracerebral availability of magnesium was also discussed by the authors of MASH-2 [1] as a possible explanation for magnesium not improving outcome after aSAH. Therefore, these pharmacokinetic findings presented here are important and may serve as a basis for discussion of future preclinical and clinical investigations carried out to identify the therapeutic role of intravenous magnesium application in preventing acute or delayed brain ischemia in SAH and stroke.

As a relevant limitation of this study, and as mentioned before, the authors would like to underline that for some patients, it was not possible to collect daily samples due to technical reasons, such as clotted external drains. This could possibly lead to a collection bias and a misinterpretation of the results.

Continuous intravenous application of magnesium sulphate results in an increase of $\left[\mathrm{Mg}^{2+}\right]_{\mathrm{CSF}}$ and $\left[\mathrm{Mg}^{2+}\right]_{\mathrm{MDS}}$, the latter presumably representing an increase of $\left[\mathrm{Mg}^{2+}\right]_{\text {ecf }}$. A significant and positive correlation of $\left[\mathrm{Mg}^{2+}\right]_{\text {serum }}$ and $\left[\mathrm{Mg}^{2+}\right]_{\mathrm{MDS}}$ was shown. This pharmacokinetic association has not been shown before and underlines one of the therapeutic principles in induced hypermagnesemia in aSAH. Hence, these findings add to the discussion of neuroprotective and antivasospastic therapy in the context of recently failed magnesium trials.

\section{References}

[1] Dorhout Mees, S.M., Algra, A., Vandertop, W.P., et al. (2012) Magnesium for Aneurysmal Subarachnoid Haemorrhage (MASH-2): A Randomised Placebo-Controlled Trial. The Lancet, 380, 44-49. http://dx.doi.org/10.1016/S0140-6736(12)60724-7

[2] Golan, E., Vasquez, D.N., Ferguson, N.D., et al. (2012) Prophylactic Magnesium for Improving Neurologic Outcome after Aneurysmal Subarachnoid Hemorrhage: Systematic Review and Meta-Analysis. Journal of Critical Care, 28, 173-181.

[3] Ram, Z., Sadeh, M., Shacked, I., et al. (1991) Magnesium Sulfate Reverses Experimental Delayed Cerebral Vasospasm after Subarachnoid Hemorrhage in Rats. Stroke, 22, 922-927. http://dx.doi.org/10.1161/01.STR.22.7.922

[4] Boet, R. and Mee, E. (2000) Magnesium Sulfate in the Management of Patients with Fisher Grade 3 Subarachnoid Hemorrhage: A Pilot Study. Neurosurgery, 47, 602-606; Discussion: 606-607.

[5] Barile, M., van De Wyngaert, F., Mbia, J.J., et al. (2003) Intravenous Magnesium Sulfate Administration in a Patient 
with Refractory Vasospasm Following Subarachnoid Hemorrhage. Intensive Care Medicine, 29, 1182-1185. http://dx.doi.org/10.1007/s00134-003-1752-9

[6] van den Bergh, W.M., Albrecht, K.W., Berkelbach van der Sprenkel, J.W., et al. (2003) Magnesium Therapy after Aneurysmal Subarachnoid Haemorrhage: A Dose-Finding Study for Long Term Treatment. Acta Neurochirurgica, 145, 195-199; Discussion: 199. http://dx.doi.org/10.1007/s00701-002-1064-9

[7] Crago, E., Kerr, M.A., Levy, E.I., et al. (2004) Effect of continuous Magnesium Infusion on Cerebral Vasospasm and Three Months Outcome Following Subarachnoid Hemorrhage. Critical Care Medicine, 32, A19. http://dx.doi.org/10.1097/00003246-200412001-00074

[8] Westermaier, T., Zausinger, S., Baethmann, A., et al. (2005) Dose Finding Study of Intravenous Magnesium Sulphate in Transient Focal Cerebral Ischemia in Rats. Acta Neurochirurgica, 147, 525-532; Discussion: 532. http://dx.doi.org/10.1007/s00701-005-0496-4

[9] Nowak, L., Bregestovski, P., Ascher, P., et al. (1984) Magnesium Gates Glutamate-Activated Channels in Mouse Central Neurones. Nature, 307, 462-465. http://dx.doi.org/10.1038/307462a0

[10] Reinhart, R.A. (1991) Clinical Correlates of the Molecular and Cellular Actions of Magnesium on the Cardiovascular System. American Heart Journal, 121, 1513-1521. http://dx.doi.org/10.1016/0002-8703(91)90160-J

[11] McLean, R.M. (1994) Magnesium and Its Therapeutic Uses: A Review. The American Journal of Medicine, 96, 63-76. http://dx.doi.org/10.1016/0002-9343(94)90117-1

[12] Lindefors, N., Amberg, G. and Ungerstedt, U. (1989) Intracerebral Microdialysis: I. Experimental Studies of Diffusion Kinetics. Journal of Pharmacological Methods, 22, 141-156. http://dx.doi.org/10.1016/0160-5402(89)90011-9

[13] (2001) Fachinformationen Mg 5-Sulfat Amp. 10\% [Summary of Product Characteristics].

[14] Gee, J.B., Corbett, R.J., Perlman, J., et al. (2004) The Effects of Systemic Magnesium Sulfate Infusion on Brain Magnesium Concentrations and Energy State during Hypoxia-Ischemia in Newborn Miniswine. Pediatric Research, 55, 93-100. http://dx.doi.org/10.1203/01.PDR.0000099771.39629.E5

[15] Lin, M.C., Huang, Y.L., Liu, H.W., et al. (2004) On-Line Microdialysis-Graphite Furnace Atomic Absorption Spectrometry in the Determination of Brain Magnesium Levels in Gerbils Subjected to Cerebral Ischemia/Reperfusion. The Journal of the American College of Nutrition, 23, 561S-565S. http://dx.doi.org/10.1080/07315724.2004.10719404

[16] Cheng, S.M., Yang, D.Y., Lee, C.P., et al. (2007) Effects of Magnesium Sulfate on Dynamic Changes of Brain Glucose and Its Metabolites during a Short-Term Forced Swimming in Gerbils. European Journal of Applied Physiology, 99, 695-699. http://dx.doi.org/10.1007/s00421-006-0374-7

[17] Lin, J.Y., Chung, S.Y., Lin, M.C., et al. (2002) Effects of Magnesium Sulfate on Energy Metabolites and Glutamate in the Cortex during Focal Cerebral Ischemia and Reperfusion in the Gerbil Monitored by a Dual-Probe Microdialysis Technique. Life Sciences, 71, 803-811. http://dx.doi.org/10.1016/S0024-3205(02)01738-1

[18] Goodman, J.C., Valadka, A.B., Gopinath, S.P., et al. (1999) Simultaneous Measurement of Cortical Potassium, Calcium, and Magnesium Levels Measured in Head Injured Patients Using Microdialysis with Ion Chromatography. Acta Neurochirurgica Supplement, 75, 35-37. http://dx.doi.org/10.1007/978-3-7091-6415-0_8

[19] Wong, G.K., Yeung, D.K., Ahuja, A.T., et al. (2009) Intracellular Free Magnesium of Brain and Cerebral Phosphorus-Containing Metabolites after Subarachnoid Hemorrhage and Hypermagnesemic Treatment: A ${ }^{31}$ P-Magnetic Resonance Spectroscopy Study. Journal of Neurosurgery, 113, 763-769. http://dx.doi.org/10.3171/2009.10.JNS09915

[20] McKee, J.A., Brewer, R.P., Macy, G.E., et al. (2005) Analysis of the Brain Bioavailability of Peripherally Administered Magnesium Sulfate: A Study in Humans with Acute Brain Injury Undergoing Prolonged Induced Hypermagnesemia. Critical Care Medicine, 33, 661-666. http://dx.doi.org/10.1097/01.CCM.0000156293.35868.B2 